\title{
Effects of dietary oleic-rich oils (virgin olive and high-oleic-acid sunflower) on vascular reactivity in Wistar-Kyoto and spontaneously hypertensive rats
}

\author{
M. D. Herrera ${ }^{1}$, C. Pérez-Guerrero ${ }^{1}$, E. Marhuenda ${ }^{1}$ and V. Ruiz-Gutiérrez ${ }^{2} *$ \\ ${ }^{1}$ Departamento de Farmacología, Facultad de Farmacia, C/Profesor García González s/n, 41012 Sevilla, Spain \\ ${ }^{2}$ Instituto de la Grasa (CSIC), Avda, Padre García Tejero no. 4, 41012 Sevilla, Spain
}

(Received 18 September 2000 - Revised 23 February 2001 - Accepted 3 April 2001)

\begin{abstract}
The effects of two monounsaturated fatty acid (MUFA)-rich diets, containing virgin olive oil (OO) and high-oleic-acid sunflower oil (HOSO), on development of vascular response from isolated thoracic rat aorta and lipid composition and fatty acid composition were studied and compared with samples from rats fed on a control diet. Dietary MUFA oils were fed for 6 weeks to spontaneously hypertensive (SHR) and Wistar-Kyoto (WKY) rats from 4 weeks of age. The maximum contraction of aortic ring preparations in response to phenylephrine $\left(10^{-6} \mathrm{M}\right)$ was significantly decreased in SHR rats fed with OO (0.81 (SEM 0.05) v. 1.18 (SEM 0.09) $g, P<0.01$ ) and treatment with HOSO did not alter the phenylephrine-induced contractions. The relaxant responses to acetylcholine $\left(10^{-5} \mathrm{M}\right.$ ) were significantly enhanced (30.03 (SEM 0.70) v. 18.47 (SEM $0.28) \%, P<0 \cdot 001)$ in the rings from SHR rats treated with OO, and were more pronounced than in WKY rats $(P<0 \cdot 05)$. In the same way, $\mathrm{OO}$ attenuated the dose-response curves induced by phenylephrine $\left(10^{-8}-10^{-5} \mathrm{M}\right)$ from SHR rats, accompained with a slower contraction. These results suggest that only the chronic feeding of $\mathrm{OO}$ diet was able to attenuate the vascular response of rat aorta. In addition, an increase in phospholipid content (186.7 (SD 3.2) v. 159.1 (SD $11.3) \mathrm{g} / \mathrm{kg}, P<0.01$ ) and changes in the fatty acid composition of aorta (mainly a decrease in arachidonic acid) could contribute to improving endothelial function. Therefore, the effects can not be attributed exclusively to the content of MUFA (mainly oleic acid). Other components of $\mathrm{OO}$, such as polyphenols, not present in HOSO, may help to explain the vascular protective effect of $\mathrm{OO}$ consumption.
\end{abstract}

Olive oil: High-oleic-acid sunflower oil: Vascular reactivity: Rat aorta

Hypertension is characterized by an increased sensitivity of vascular smooth muscle to vasoconstrictor stimuli (Triggle \& Laher, 1985; Bohr \& Webb, 1988). Hyperactivity to vasoactive agonists has been correlated with an enhanced protein kinase C activity (Turla \& Webb, 1987; Silver et al. 1992; Bazan et al. 1993), an augmented phosphoinositide metabolism (Turla \& Webb, 1990), and an increased $\mathrm{Ca}^{2+}$ mobilisation (ThorinTrescases et al. 1994). The endothelium plays an important role in controlling the $\alpha$-agonist-induced contraction and the reduced influence of the endothelium in the stroke-prone spontaneously hypertensive (SHR) rats aorta is most likely to be due to a decreased activity of this endothelium (Osugi et al. 1990). The changes in endothelium-dependent relaxation may also affect the contractile response of blood vessels and, as a consequence, may be involved in controlling blood pressure (Shirasaki et al. 1988; Tesfamariam \& Halpern, 1988). In fact, the vascular endothelial function has been shown to be impaired in blood vessels of hypertensive animal models (Sunano et al. 1989), as well as in patients with essential hypertension (Egashira et al. 1995; Taddei et al. 1995).

The Mediterranean region has a very low prevalence of cardiovascular disease. The life expectation in Mediterranean countries is currently greater than that in countries of northern Europe and in the USA. However, the mechanisms underlying the cardiovascular benefits of Mediterraneanstyle diets and the effect on endothelial dysfunction are not fully understood (Massaro et al. 1999; Tsimikas et al. 1999). The diet consumed by these populations have a common characteristic, namely the high proportion of olive oil (OO;

Abbreviations: HOSO, high-oleic-acid sunflower oil; MUFA, monounsaturated fatty acids; OO, olive oil.

* Corresponding author: Dr Ruiz-Gutiérrez, fax +34 954 616790, email valruiz@cica.es 
rich in monounsaturated fatty acids (MUFA), mainly oleic acid), whereas the northern European diet includes a large proportion of saturated animal fats (Keys, 1995).

Despite OO being the most common highly monounsaturated oil used for nutritional studies to evaluate the effects of MUFA-enriched diets (mainly oleic acid), other sources of dietary MUFA (such as high-oleic-acid sunflower oil; HOSO) are now becoming available. However, there is virtually no information concerning their effects on endothelial function. It is of interest that the beneficial effects of dietary $\mathrm{OO}$ are not found to be the same as for the HOSO-rich diet, despite the fact that both vegetable oils provide a similar concentration of MUFA (Ruiz-Gutiérrez et al. 1996, 1999). Therefore, the wealth of minor components (including various polyphenols, such as oleuropein) contained in the unsaponificable fraction of virgin OO (Monteodoro et al. 1992) and not present in HOSO, appears to be the key to the beneficial effects of virgin OO on cardiovascular events (Visioli \& Galli, 1994, 1995).

The present work has been designed to compare the effects of two diets rich in oleic acid (from virgin $\mathrm{OO}$ and from refined HOSO) and a control diet, on the vascular reactivity of Wistar-Kyoto (WKY) rats and SHR rats, in order to provide the first evidence of the effects and mechanisms of action of both oils on endothelial dysfunction present in blood vessels of the hypertensive animal model. In addition, we evaluated the effects of both MUFA diets on lipid and fatty acid composition phospholipids of the vascular wall, in order to document further the beneficial effects on endothelial function.

\section{Methods}

\section{Animals and composition of experimental diets}

Male SHR and WKY rats were obtained at the age of 4 weeks from Harlan Interfauna Ibérica, S.A. (Barcelona, Spain). They were housed at $24 \pm 2^{\circ} \mathrm{C}$ with $60 \pm 20 \%$ relative humidity, with a $12 \mathrm{~h}$ light-dark cycle. All experiments were performed on 10-12-week-old rats.

Both SHR and WKY rats were divided into three groups of six animals each. Each group was fed on one of the following diets for 6 consecutive weeks: a semisynthetic diet (basal diet) with $20 \mathrm{~g}$ unspecified lipid $/ \mathrm{kg}$, purchased from Panlab SRL (Barcelona, Spain) (control group) or basal diet modified by supplemention with $100 \mathrm{~g}$ virgin $\mathrm{OO}$ (Olea europea) $/ \mathrm{kg}$ (OO group) or $100 \mathrm{~g} \mathrm{HOSO}$ (Helianthus annus) $/ \mathrm{kg}$ (HOSO group). The composition of the experimental diets is shown in Table 1. To minimise oxidation, all diets were prepared once per week and stored at $4^{\circ} \mathrm{C}$ under an atmosphere of $\mathrm{N}_{2}$ until needed. Changes in composition were not detected during storage.

The fatty acid composition of the oils was analysed and is shown in Table 2 . The non-fatty acid components of the oils are presented in Table 3.

\section{Pharmacological measurements}

The experiments were performed on the thoracic aorta of male SHR and normotensive WKY rats. After 6 weeks of
Table 1. Composition of experimental diets $(\mathrm{g} / \mathrm{kg})$

\begin{tabular}{lccc}
\hline Ingredients & Control & OO & HOSO \\
\hline Casein & 209 & 203 & 203 \\
Sucrose & 450 & 374 & 374 \\
Cornstarch & 202 & 180 & 180 \\
Lipid & 20 & 20 & 20 \\
OO & - & 100 & - \\
HOSO & - & - & 100 \\
Cellulose powder & 52 & 56 & 56 \\
Mineral mix* & 57 & 57 & 57 \\
Vitamin mix† & 10 & 10 & 10 \\
Total energy (MJ) & $15 \cdot 2$ & $17 \cdot 1$ & $17 \cdot 1$ \\
Protein (\% energy) & $23 \cdot 1$ & $19 \cdot 7$ & $19 \cdot 7$ \\
Lipid (\% energy) & $4 \cdot 9$ & $26 \cdot 3$ & $26 \cdot 3$ \\
Carbohydrate (\% energy) & 71.9 & $53 \cdot 9$ & $53 \cdot 9$ \\
\hline
\end{tabular}

OO, olive oil; HOSO, high-oleic-acid sunflower oil.

${ }^{*}$ Mineral mix $(\mathrm{g} / \mathrm{kg})$ : $\mathrm{NaCl} 139.3, \mathrm{~K}_{2} \mathrm{HPO}_{4} 386.1, \mathrm{CaCO}_{3} 381.4, \mathrm{Mg}$ $\mathrm{SO}_{4} \cdot 7 \mathrm{H}_{2} \mathrm{O} 57 \cdot 3, \mathrm{FeSO}_{4} \cdot 7 \mathrm{H}_{2} \mathrm{O} 27 \cdot 0, \mathrm{MnSO}_{4} \cdot \mathrm{H}_{2} \mathrm{O} 4 \cdot 0, \mathrm{ZnSO}_{4} \cdot 7 \mathrm{H}_{2} \mathrm{O}$ 1.25, $\mathrm{KI} 0.8, \mathrm{CuSO}_{4} .5 \mathrm{H}_{2} \mathrm{O} 0.5, \mathrm{CoCl}_{2} .6 \mathrm{H}_{2} \mathrm{O} 0.02$.

†Vitamin mix $(/ \mathrm{kg})$ : retinol $5.9 \mathrm{mg}$, cholecalciferol $0.15 \mathrm{mg}$, thiamin $20 \mathrm{mg}$, riboflavin $15 \mathrm{mg}$, nicotinic acid $70 \mathrm{mg}$, pyridoxine $10 \mathrm{mg}$, inositol $150 \mathrm{mg}$, cyanocobalamin $50 \mu \mathrm{g}$, $\alpha$-tocopherol $170 \mathrm{mg}$, phylloquinone $40 \mathrm{mg}$, choline $1.36 \mathrm{~g}$, folic acid $5 \mathrm{mg}, p$-aminobenzoic acid $50 \mathrm{mg}$, biotin $0.3 \mathrm{mg}$.

Table 2. Fatty acid composition ( $\mathrm{g} / \mathrm{kg}$ total fat) of the experimental oils

\begin{tabular}{llrr}
\hline Fatty acid & Control & OO & HOSO \\
\hline $16: 0$ & 132 & 118 & 43 \\
$16: 1 n-9$ & 12 & 9 & 1 \\
$17: 0$ & - & 4 & 1 \\
$18: 0$ & 31 & 28 & 47 \\
$18: 1 n-9$ & 368 & 792 & 802 \\
$18: 2 n-6$ & 417 & 35 & 94 \\
$18: 3 n-3$ & 41 & 6 & 1 \\
$20: 0$ & - & 3 & 4 \\
$20: 1 n-9)$ & - & 2 & 2 \\
$24: 0$ & - & 4 & 4 \\
\hline
\end{tabular}

OO, olive oil; HOSO, high-oleic-acid sunflower oil.

Table 3. Composition of non-fatty acid components of the experimental oils

\begin{tabular}{lcr}
\hline Non-fatty acid & OO & HOSO \\
\hline Total unsaponifiable fraction $(\mathrm{g} / \mathrm{kg})$ & 15 & 10 \\
Total sterols $(\mathrm{mg} / \mathrm{kg})$ & 1357 & 1534 \\
Cholesterol $(\mathrm{g} / \mathrm{kg})$ & $1 \cdot 7$ & $0 \cdot 1$ \\
Brasicasterol $(\mathrm{g} / \mathrm{kg})$ & - & $1 \cdot 2$ \\
Campesterol $(\mathrm{g} / \mathrm{kg})$ & $3 \cdot 8$ & $102 \cdot 5$ \\
Stigmasterol $(\mathrm{g} / \mathrm{kg})$ & $8 \cdot 1$ & $115 \cdot 9$ \\
$\beta$-Sitosterol $(\mathrm{g} / \mathrm{kg})$ & $939 \cdot 9$ & $593 \cdot 5$ \\
$\Delta-5$-Avenasterol $(\mathrm{g} / \mathrm{kg})$ & - & $28 \cdot 8$ \\
$\Delta$-7-Stigmasterol $(\mathrm{g} / \mathrm{kg})$ & $2 \cdot 2$ & $118 \cdot 4$ \\
$\Delta$-7-Avenasterol $(\mathrm{g} / \mathrm{kg})$ & $1 \cdot 5$ & $32 \cdot 7$ \\
Squalene $(\mathrm{mg} / \mathrm{kg})$ & 3000 & 90 \\
Tocopherols $(\mathrm{mg} / \mathrm{kg})$ & 47 & 484 \\
$\alpha-$ Tocopherol $(\mathrm{mg} / \mathrm{kg})$ & 34 & 484 \\
$\gamma$-Tocopherol $(\mathrm{mg} / \mathrm{kg})$ & 13 & - \\
Fraction of polyphenols $(\mathrm{mg} / \mathrm{kg})$ & 300 & - \\
Total polyphenols $(\mathrm{mg} / \mathrm{kg})$ & 322 & - \\
Orthodiphenol $(\mathrm{mg} / \mathrm{kg})$ & 22 & - \\
\hline
\end{tabular}

OO, olive oil; HOSO, high-oleic-acid sunflower oil. 
receiving the respective diets (10-week-old animals), the rats were killed by a blow on the head and the descending thoracic aorta was rapidly dissected and placed in a modified Krebs-Henseleit solution, containing (mM): $\mathrm{NaCl}$ 118, $\mathrm{KCl} 4 \cdot 75, \mathrm{NaHCO}_{3} 25, \mathrm{MgSO}_{4} 1 \cdot 2, \mathrm{CaCl}_{2} 1 \cdot 8$, $\mathrm{KH}_{2} \mathrm{PO}_{4} 1 \cdot 2$, glucose 11. After excess fat and connective tissue were removed, the aorta was cut into $2-3 \mathrm{~mm}$ rings. Aortic rings were mounted under the basal tension of $1 \boldsymbol{g}$ in $20 \mathrm{ml}$ organ baths containing modified krebs-Henseleit solution and attached to a force-displacement transducer (Pioden UF-1, Harvard, Kent, UK) to isometric contraction force as previously described (Herrera et al. 1996). The signal was recorded by a Powerlab ${ }^{\circledR}$ data acquisition system (AD Instruments, Castle Hill, Australia). The tissue bath was maintained at $37^{\circ} \mathrm{C}$ and bubbled with a $\mathrm{O}_{2}-\mathrm{CO}_{2}$ (95:5, $\mathrm{v} / \mathrm{v})$. All experiments were performed on aortic rings with endothelium. The presence of endothelium was confirmed by the occurrence of relaxations induced by acetylcholine $\left(10^{-5} \mathrm{M}\right)$ in rings contracted with noradrenaline $\left(10^{-5} \mathrm{M}\right)$. Each preparation was allowed to equilibrate for at least 90 min prior to initiation of experimental procedures and during this period the incubation media were changed every $20 \mathrm{~min}$. After equilibrations, the following experiments were performed: (1) aortic rings were contracted by single submaximal concentrations of $10^{-6} \mathrm{M}$ phenylephrine. When the contractile response to the agonist was stable, acetylcholine was added $\left(10^{-5} \mathrm{M}\right)$ in order to analyse the endothelium-dependent vasodilating response (Alvarez de Sotomayor et al. 1999). All results were expressed as a percentage of the maximal contraction of phenylephrine induced responses; (2) dose-response curves for phenylephrine-induced contraction in endothelium-intact preparations. The cumulative concentration-response curve was obtained with phenylephrine $\left(10^{-8}-10^{-5} \mathrm{M}\right)$ at $3 \mathrm{~min}$ intervals. Different aortic rings were used in each experiment.

\section{Extraction and separation of lipids}

The intima were carefully scraped with glass slides. Extraction of total lipids from intima scrapings was carried out following the method of Folch et al. (1957) in the presence of butylated hydroxytoluene as antioxidant. Tissue dissociation was achieved by homogenization in ice-cold chloroform-methanol $(2: 1, \quad(\mathrm{v} / \mathrm{v})$ containing $0.001 \mathrm{ml}$ butylated hydroxytoluene/l using an UltraTurrax homogeniser (model Type TP-18-1, Ultra Turrax, Vineland, NJ, USA).

Total lipids were quantified by means of the Iatroscan TLC/FID technique (De Schrijver \& Vermeulen 1991). The Iatroscan MK-5, Iatron Laboratories Inc., Tokyo, Japan was used in combination with Chromarods S Iatron Laboratories Inc., Tokyo, Japan having a precoated thin active layer of silica. Chromarods $\mathrm{S}$ were routinely stored in $4.5 \mathrm{M}-\mathrm{H}_{2} \mathrm{SO}_{4}$. Prior to use, the rods were washed with distilled water, dried at $110^{\circ} \mathrm{C}$ for $15 \mathrm{~min}$ and activated by passing through the flame of the Iatroscan detector. Total lipids or phospholipids $(3 \mu 1)$ were spotted on each rod using a $10 \mu$ l Hamilton syringe. To separate total lipids, rods were developed in hexane-diethyl ether-formic acid (90:10:2, by vol.). The phospholipids were resolved in two steps, starting with an initial development of rods in chloroform-methanol-acetic acid-water, (67:28:2:3, by vol.), drying at $70^{\circ} \mathrm{C}$ for $10 \mathrm{~min}$, then a second development in hexane-diethyl ether-formic acid (90:10:2, by vol.). Rods were scanned under the following conditions: $\mathrm{H}_{2}$ flow $175 \mathrm{ml} / \mathrm{min}$, air flow $1850 \mathrm{ml} /$ min, scanning speed $47 \mathrm{~mm} / \mathrm{s}$, chart speed $42 \mathrm{~mm} / \mathrm{min}$. An Iatrocorder TC-11 integrator, New Technology System, Rome, Italy, was used for recording and area integration (Ruiz-Gutiérrez et al. 1995).

\section{Fatty acid analysis}

Lipids from the samples were separated by TLC on plates of silica gel 60 (Kieselgel 60 F254; Merck, Barcelona, Spain) using a solvent system of hexane-diethyl ether-acetic acid (80:20:1, by vol.). After development of the plate, the solvent was allowed to evaporate. This system separates phospholipids, cholesterol, triacylglycerol and cholesteryl esters in increasing order of $\mathrm{Rf}$ (distance of spot centre from start point/distance of solvent front from start point). Individual lipid zones were scraped from TLC plates and eluted from the silica gel with chloroform-methanol $(2: 1$, $\mathrm{v} / \mathrm{v}$ ) according to the individual lipids. Fatty acid contents were determined by GC, as previously described (RuizGutiérrez et al. 1992; Muriana et al. 1995).

\section{Fatty acid methyl ester analysis}

Phospholipids were saponified by heating for $25 \mathrm{~min}$ with $5 \mathrm{ml}$ of $0.2 \mathrm{M}$-sodium methylate at $120^{\circ} \mathrm{C}$ and heated again at $80^{\circ} \mathrm{C}$ for $25 \mathrm{~min}$ with $60 \mathrm{~g} \mathrm{H}_{2} \mathrm{SO} / 1$ anhydrous methanol. The fatty acid methyl esters thus formed were eluted with hexane and analysed in a Hewlett-Packard 5890 series II GC (Hewlett-Packard Co., Avondale, PA, USA) equipped with a flame ionization detector and using an Omegawax 320 fused-silica capillary column $(30 \mathrm{~m} \times 0.32 \mathrm{~mm}$ i.d., $0.25 \mu \mathrm{m}$ film), obtained from Supelco (Bellafonte, PA, USA). The initial column temperature was $200^{\circ} \mathrm{C}$, which was held for $10 \mathrm{~min}$, then programmed to change from 200 to $230^{\circ} \mathrm{C}$ at $2^{\circ} \mathrm{C} / \mathrm{min}$. Peak areas were calculated by a Hewlett-Packard $3390 \mathrm{~A}$ recording integrator. Individual fatty acid methyl esters were identified on isothermal runs by comparison of their retention times against those of standards. Fatty acid methyl esters for which no standard was available were quantified using calibration tables of relative response ratios constructed according to $\mathrm{C}$ number using $\mathrm{GC}$-mass spectrometry, performed on a Hewlett-Packard 5890 GC interfaced directly to an AEJ MS30/70 VG mass spectrometer (VG Analytical, Manchester, UK), using the electron impact ionization mode. The ion source temperature was maintained at $200^{\circ} \mathrm{C}$, the multiplier voltage was $4.0 \mathrm{kV}$, the emision current was $100 \mu \mathrm{A}$ and the electron energy was $70 \mathrm{eV}$. The data were processed with a VG 11/ 250 data system (VG Analytical).

\section{Non-fatty acid components}

For the extraction of the unsaponifiable matter, $20 \mathrm{~g}$ oils were saponified for $30 \mathrm{~min}$ with $75 \mathrm{ml} \mathrm{KOH}(100 \mathrm{~g} / \mathrm{l}$ ethanol). The solution was put in a $5000 \mathrm{ml}$ decanting funnel, $100 \mathrm{ml}$ distilled water was added, and the mixture was extracted with $100 \mathrm{ml}$ aliquots of hexane. The hexane 
solution was evaporated to dryness in a rotary evaporator at $30^{\circ} \mathrm{C}$ under reduced pressure. The sterol fraction was analysed by capillary GLC (Garcia Regueiro et al. 1994). Tocopherols were analysed by HPLC (Kramer et al. 1997). For the assay of squalene, the hydrocarbon fraction was separated from the oils by column cromatography on silica gel and analysed by capillary GLC (Sulpioce \& Ferezou, 1984). The polyphenol fraction was determined by capillary GLC (Arce et al. 1998).

\section{Drugs}

Lipid and phospholipid standards were obtained from Sigma Chemical Co, (St Louis, MO, USA). Fatty acid methyl ester/standards were obtained from Larodan Fine Chemicals (Malmo, Sweden). The internal standard solution was prepared by dissolving $200 \mathrm{mg}$ tricosanoic acid methyl ester (23:0) in $100 \mathrm{ml}$ hexane. The calibration solutions were prepared by dissolving known amounts of fatty acid methyl ester standards in hexane containing butylated hydroxytoluene (2,6-di-tert-butyl-p-cresol) obtained from Sigma (Poole, Dorset, UK).

For pharmacological experiments, the following drugs were used: noradrenaline bitartrate, acetylcholine chloride and phenylephrine chloride, all obtained from Sigma Chemical Co. The drugs were dissolved in distilled water.

\section{Statistical analysis}

Results are expressed as mean values with their standard errors (pharmacological experiments) or mean values and standard deviations (lipid and fatty acid composition) of preparations obtained from at least six animals per group. One-way ANOVA followed by Bonferroni tests were used for statistical analysis. $P$ values $<0.05$ were considered as showing a significant difference. The analyses were performed with the GraphPad Prism ${ }^{\circledR}$ statistical package (version 2.01, 1996; Graphpad Software Inc., San Diego, USA).

\section{Results}

Effects of virgin olive oil and high-oleic-acid sunflower oil on vascular reactivity in Wistar-Kyoto and spontaneously hypertensive rats

During contractions caused by phenylephrine $\left(10^{-6} \mathrm{M}\right)$ for $15 \mathrm{~min}$, addition of acetylcholine $\left(10^{-5} \mathrm{M}\right)$ evoked endothelium-dependent relaxation in aortic ring of WKY and SHR rats (Fig. 1).

The maximum phasic contraction in response to phenylephrine $\left(10^{-6} \mathrm{M}\right)$ was greater $(P<0 \cdot 01)$ in aortic rings from SHR (1.18 (SEM 0.09) $g$ ) than from WKY (0.88 (SEM 0.14) g) rats. This contraction was significantly decreased in aorta from SHR rats fed with OO (0.81 (SEM $0 \cdot 05), \boldsymbol{g}, P<0.01)$ but not in those from WKY rats $(0.89$
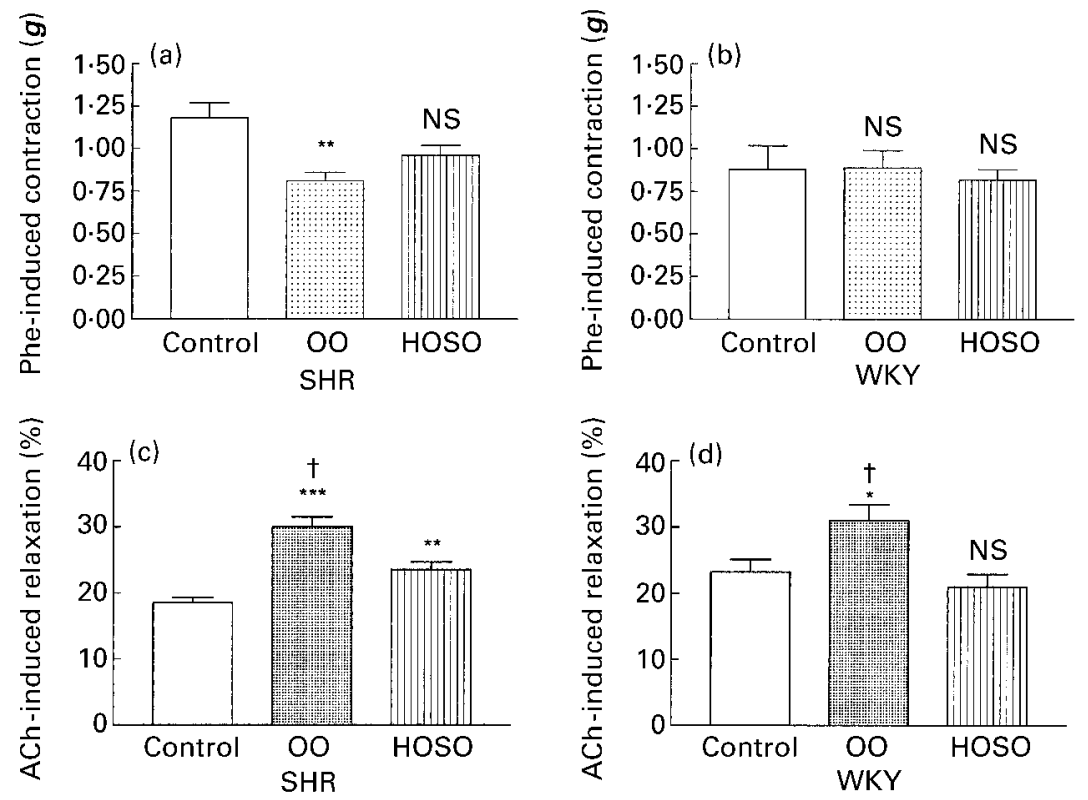

Fig. 1. Evaluation of maximum vascular responses for phenylephrine (Phe)-induced contraction $(\boldsymbol{g})(\mathrm{a}, \mathrm{b})$ and maximum vascular responses for acetylcholine (ACh)induced relaxation (\%) (c, d) in rat isolated aorta preparations obtained from control rats, and from those receiving an olive oil (OO)- or a high-oleic-acid sunflower (HOSO)enriched diet. SHR, Spontaneously hypertensive rats; WKY, Wistar-Kyoto rats. For details of diets and procedures, see Tables 1-3 and p. 350. Values are means for six rats per group with their standard errors represented by vertical bars. Mean values were significantly different from those of the control group: * $P<0.05$, ${ }^{* *} P<0.01$, ${ }_{* * *} P<0.001$. Mean value was significantly different from that of the HOSO diet group; $\dagger P<0.01$. 

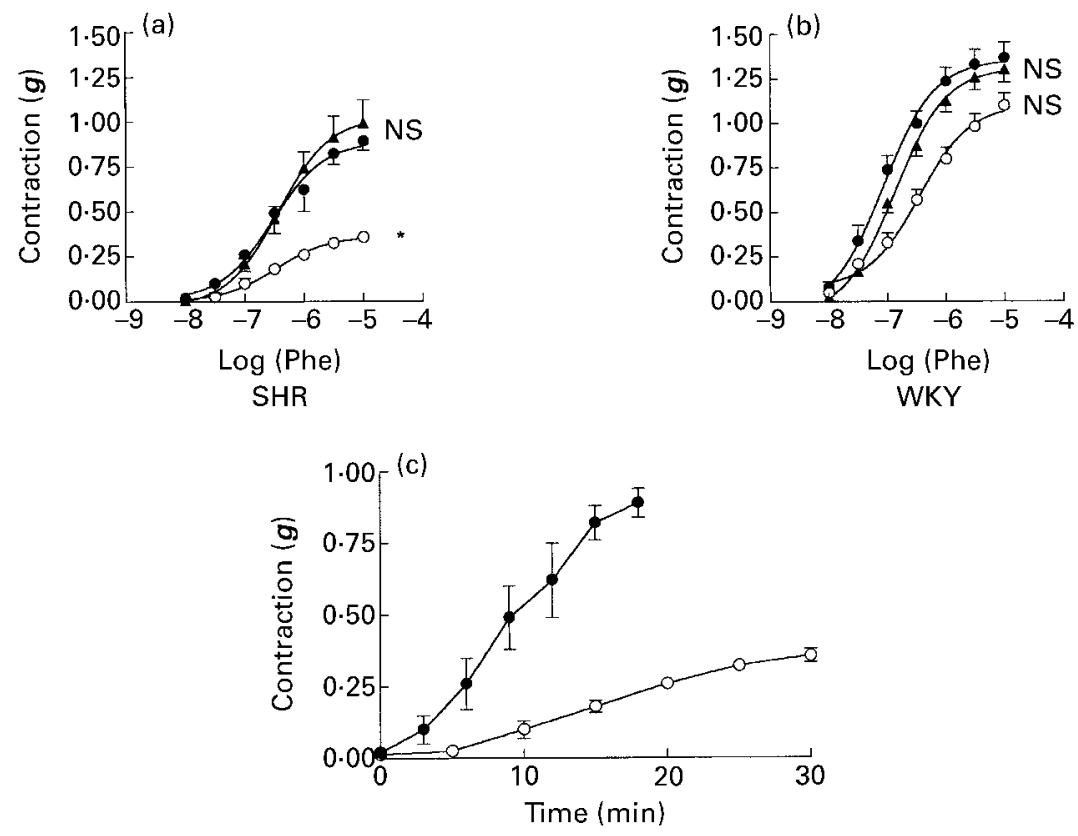

Fig. 2. Dose-response curves for phenylephrine (Phe)-induced contractions $(\boldsymbol{g})$ in rat isolated aorta preparations obtained from control rats $(\bullet)$, and from those receiving an olive oil (OO)- (O) or a high-oliec-acid sunflower (HOSO)-enriched diet $(\mathbf{\Lambda})(\mathrm{a}, \mathrm{b})$ and mean time course (min) of Phe-induced contractions (c). Note the difference in the time course in rat isolated aorta preparations from control rats and those receiving the $\mathrm{OO}$ diet ((c), • v. O). SHR, spontaneously hypertensive rats; WKY, Wistar-Kyoto rats. For details of diets and procedures, see Tables 1-3 and p. 350. Values are means for six experiments with their standard errors represented by vertical bars. Mean value was significantly different from that of the control group: ${ }^{*} P<0.01$.

(SEM 0·10) $g$, NS.). The treatment with HOSO did not alter the phenylephrine-induced contractions (0.96 (SEM 0.06) $g$ for SHR and 0.82 (SEM 0.06) $\boldsymbol{g}$ for WKY rats) (Fig. 1).

The relaxant responses to acetylcholine $\left(10^{-5} \mathrm{M}\right)$ were significantly enhanced by treatment with OO in both SHR (30.03 (SEM 0.70), v. 18.47 (SEM 0.28) \%, $P<0.001)$ and WKY (30.97 (SEM 2.40), v. 23.23 (SEM 1.9) \%, $P<0.05$ ) rings and the increase of relaxant responses were significantly weaker in the rings from SHR rats $(23.47$ (SEM 0.36$) \%, P<0.01)$ treated with HOSO $(P<0.01 v$. OO treatment) (Fig. 1).

Dose-response curves for phenylephrine-induced contractions $\left(10^{-8}-10^{-5} \mathrm{M}\right)$ in endothelium-intact preparations from SHR and WKY rat isolated aorta were used as an indicator of $\mathrm{Ca}^{2+}$ release through the inositol 1,4,5-triphosphate receptor pathway. Phenylephrine evoked similar concentration-contraction curves in the SHR control rings and in the SHR rings from rats treated with HOSO, whereas treatment with $\mathrm{OO}$ produced a pronounced decrease of the contraction of aortic ring in response to phenylephrine affecting the attenuation of the maximal response (Fig. 2). Moreover, the time course of the contraction of this last preparation was slower, needing more time to become stable (Fig. 2)

\section{Diets}

In order to document the influence of the two experimental oils on distinct behaviour of the contractile and relaxant responses of thoracic aortas, we examined the composition of two oils exhaustively.

The fatty acid composition of $\mathrm{OO}$ and HOSO was characterized by a high content of MUFA, mainly oleic acid (about $800 \mathrm{~g} / \mathrm{kg}$ total fats) (Table 2). The major differences were greater concentrations of palmitic acid (16:0) in OO and linoleic acid (18:2) in HOSO. In relation to composition in non-fatty acid components (minor components), significant differences $(P<0 \cdot 001)$ were noted for tocopherols, squalene and polyphenols between the experimental oils (Table 3). The concentration of tocopherols was greater $(484 \mathrm{mg} / \mathrm{kg})$ in HOSO than in OO $(47 \mathrm{mg} / \mathrm{kg})$ unlike squalene content, which was $3000 \mathrm{mg} / \mathrm{kg}$ OO and $90 \mathrm{mg} / \mathrm{kg}$ HOSO. However, polyphenols were only found in OO.

Effects of virgin olive oil and high-oleic-acid sunflower oil on the lipid composition of intima aorta from Wistar-Kyoto and spontaneously hypertensive rats

Table 4 shows the effects of experimental diets on lipid composition of intima aorta from WKY and SHR rats.

The content of membrane phospholipid showed reduced in animal model of hypertension (SHR) (159.1 (SD 11.3) $\mathrm{g} / \mathrm{kg}, P<0.001)$ compared with non-hypertensive animals (WKY) (195.6 (SD 6.0) g/kg). Phospholipid concentration was increased significantly in SHR rats fed on the OO diet (186.7 (SD 3.2) $\mathrm{g} / \mathrm{kg}, P<0 \cdot 01$ ) approaching the values of control WKY rats. However, the HOSO diet led to a significant decrease in both groups of animals $(P<0.001 \mathrm{v}$. control group). The total cholesterol level remained 
Table 4. Lipid composition and distribution (\% w/w) of the major phospholipid of intima aorta from normotensive (Wistar-Kyoto; WKY) and spontaneously hypertensive (SHR) rats fed experimental dietsł

(Mean values and standard deviations for six rats per group)

\begin{tabular}{|c|c|c|c|c|c|c|c|c|c|c|c|c|}
\hline \multirow[t]{3}{*}{ Diet... } & \multicolumn{4}{|c|}{ Control } & \multicolumn{4}{|c|}{$\mathrm{OO}$} & \multicolumn{4}{|c|}{ HOSO } \\
\hline & \multicolumn{2}{|c|}{ WKY } & \multicolumn{2}{|c|}{ SHR } & \multicolumn{2}{|c|}{ WKY } & \multicolumn{2}{|c|}{ SHR } & \multicolumn{2}{|c|}{ WKY } & \multicolumn{2}{|c|}{ SHR } \\
\hline & Mean & $\overline{S D}$ & Mean & SD & Mean & SD & Mean & SD & Mean & SD & Mean & SD \\
\hline PL & $19 \cdot 56$ & 0.60 & 15.91††† & $1 \cdot 13$ & $21 \cdot 40$ & 1.59 & $18 \cdot 67^{* *}+\dagger$ & 0.32 & $16 \cdot 56^{\star \star *}$ & $2 \cdot 13$ & $12 \cdot 09^{* * *}$ 十† & 0.59 \\
\hline PE & 24.84 & 1.82 & $14.7+\dagger \dagger$ & 1.22 & $20 \cdot 41^{*}$ & 3.5 & $11 \cdot 2 \dagger+\dagger$ & 3.5 & $21 \cdot 32$ & 0.3 & $11 \cdot 2 \dagger \dagger \dagger$ & 0.3 \\
\hline PS & 1.9 & 0.21 & 1.5 & 0.21 & 2.03 & 0.7 & 1.5 & 0.9 & 2.23 & 0.32 & 1.6 & 0.3 \\
\hline PC & 27.5 & $6 \cdot 2$ & 27.5 & $6 \cdot 2$ & $27 \cdot 41$ & $1 \cdot 3$ & $27 \cdot 41$ & $1 \cdot 3$ & 28.02 & $4 \cdot 4$ & $27 \cdot 02$ & 4.4 \\
\hline SM & $45 \cdot 23$ & $6 \cdot 4$ & $55 \cdot 23+\dagger$ & $5 \cdot 4$ & 49.56 & 3.8 & $59.56+†$ & 3.8 & 48.04 & $2 \cdot 7$ & 60†t† & 0.7 \\
\hline LysoPE & 0.53 & 0.2 & 0.63 & 0.2 & 0.55 & 0.3 & 0.32 & 0.3 & 0.49 & 0.3 & 0.42 & 0.3 \\
\hline $\mathrm{CHOL}$ & $1 \cdot 28$ & 0.32 & 1.82 & 0.39 & 1.80 & 0.55 & $1 \cdot 12^{*}$ & 0.36 & 1.02 & 0.28 & 1.27 & 0.29 \\
\hline $\mathrm{TG}$ & 79.00 & 1.96 & 81.64 & 3.23 & $76 \cdot 74$ & 0.00 & $79 \cdot 72$ & 0.22 & $82 \cdot 30^{*}$ & 1.98 & $86 \cdot 56^{* *}+\dagger$ & 0.33 \\
\hline CE & 0.16 & 0.09 & $0.58 † \dagger$ & 0.03 & $0 \cdot 16$ & 0.06 & $0.52 \dagger$ & 0.12 & $0.50^{*}$ & 0.41 & $0.11^{\star *}$ & 0.01 \\
\hline
\end{tabular}

OO, olive oil; HOSO, high-oleic-acid sunflower oil; PL, phospholipid; PE, phosphatidyl ethanolamine; PS, phosphatidyl serine; PC, phosphatidyl choline; SM, sphingomyelin; LysoPE, lysophosphatidyl ethanolamine; CHOL, free cholesterol; TG, triacylglycerol; CE, cholesteryl ester.

Mean values were significantly different from those of the control group: * $P<0.05,{ }^{* *} P<0.01,{ }^{* * *} P<0.001$.

Mean values were significantly different from those of the WKY group $\dagger P<0.05$, †† $P<0.01$, $\uparrow \dagger+P<0.001$

‡For details of diets and procedures, see Tables 1-3 and p. 350.

practically unaltered in HOSO- and OO-fed groups, except for SHR treated with OO, for which the value was significantly less than the control value $(11 \cdot 2$ (SD 3.6) v. $18 \cdot 2$ (SD 3.9$) \mathrm{g} / \mathrm{kg}, P<0.05$ ) and triacylglycerol levels increased with HOSO treatment (823.0 (SD 19.8), $P<0.05$ for WKY and 865.6 (SD 3.3) $\mathrm{g} / \mathrm{kg}, P<0.01$ for SHR rats). The HOSO-fed group showed a significant decrease in the concentration of membrane esterified cholesterol in SHR rats $(1 \cdot 1(\mathrm{SD} 0 \cdot 1) v .5 \cdot 8(\mathrm{SD} 0 \cdot 3) \mathrm{g} / \mathrm{kg}, P<0 \cdot 01)$.

To determine the phospholipid composition of intimal aorta, the major phospholipid species were quantified and the results of the analyses are given in Table 4. In this table, we can observe how the major phospholipid species is sphingomyelin (SHR values greater than those from WKY, $P<0.01$ ), followed by phosphatidyl choline, phosphatidly ethanolamine (WKY values greater than those from SHR, $P<0.001$ ), phosphatidyl serine and lisophosphatidyl ethanolamine (these latter two had very low values).

Effects of virgin olive oil and high-oleic-acid sunflower oil on the phospholipid fatty acid composition of intima aorta from Wistar-Kyoto and spontaneously hypertensive rats

Table 5 shows the proportions of fatty acids $(\mathrm{g} / 100 \mathrm{~g}$ total fatty acids) in phospholipids of intima aorta in rats fed on the different diets. In the present study, the most significant

Table 5. Fatty acid composition ( $\mathrm{g} / 100 \mathrm{~g}$ total fatty acids) of phospholipids of intima aorta from normotensive (Wistar-Kyoto; WKY) and spontaneously hypertensive (SHR) rats fed experimental dietsł

(Mean values and standard deviations for six rats per group)

\begin{tabular}{|c|c|c|c|c|c|c|c|c|c|c|c|c|}
\hline \multirow{3}{*}{$\begin{array}{l}\text { Diet... } \\
\text { Fatty acid }\end{array}$} & \multicolumn{4}{|c|}{ Control } & \multicolumn{4}{|c|}{$\mathrm{OO}$} & \multicolumn{4}{|c|}{ HOSO } \\
\hline & \multicolumn{2}{|c|}{ WKY } & \multicolumn{2}{|c|}{ SHR } & \multicolumn{2}{|c|}{ WKY } & \multicolumn{2}{|l|}{ SHR } & \multicolumn{2}{|c|}{ WKY } & \multicolumn{2}{|l|}{ SHR } \\
\hline & Mean & SD & Mean & SD & Mean & SD & Mean & SD & Mean & SD & Mean & SD \\
\hline $16: 0$ & 12.99 & $2 \cdot 65$ & 18.03††† & 0.09 & $13 \cdot 92$ & 0.86 & $15 \cdot 80$ & 0.86 & $11 \cdot 62$ & $1 \cdot 49$ & 16.15††† & 1.49 \\
\hline $16: 1 n-9$ & $2 \cdot 81$ & 0.77 & $2 \cdot 39$ & 0.02 & $3 \cdot 28$ & 0.19 & $1.47^{* \star} † \dagger †$ & 0.19 & $1 \cdot 63^{\star * \star}$ & 0.17 & $1 \cdot 10^{\star \star \star}$ & 0.17 \\
\hline 18:0 & $22 \cdot 76$ & $3 \cdot 76$ & $22 \cdot 05$ & $1 \cdot 32$ & $21 \cdot 54$ & $1 \cdot 50$ & $17 \cdot 81$ & $1 \cdot 50$ & $22 \cdot 88$ & $2 \cdot 69$ & $22 \cdot 69$ & 2.69 \\
\hline $18: 1 n-9$ & $17 \cdot 95$ & $2 \cdot 33$ & $17 \cdot 53$ & 1.66 & $27 \cdot 59^{\star * *}$ & 0.42 & $32 \cdot 58^{* * *} \dagger \dagger 十$ & 0.42 & $22 \cdot 87^{\star \star *}$ & 0.07 & $22 \cdot 34^{\star * *}$ & 0.07 \\
\hline $18: 1 n-7$ & $5 \cdot 85$ & $1 \cdot 22$ & 3.42††† & 0.01 & $3.89^{\star * *}$ & 0.01 & $3 \cdot 82$ & 0.42 & $3.93^{\star * *}$ & 0.00 & $2.72 † \dagger$ & 0.08 \\
\hline $18: 2 n-6$ & 13.91 & $1 \cdot 35$ & $13 \cdot 45$ & 0.01 & $8 \cdot 16^{\star \star *}$ & $0 \cdot 10$ & $9 \cdot 05^{\star \star \star}$ & $0 \cdot 10$ & 13.96 & 0.03 & $10 \cdot 24^{\star * \star *}$ 十七 & 0.03 \\
\hline $20: 0$ & 0.38 & 0.01 & $0.1 \dagger † \dagger$ & 0.01 & 0.38 & 0.03 & $0.14 † \dagger †$ & 0.03 & 0.39 & 0.02 & $0.85^{\star * *}$ 十七十 & 0.04 \\
\hline $20: 3 n-6$ & 2.07 & 0.63 & $1.07 \dagger$ & 0.63 & $1.03^{*}$ & 0.01 & $2 \cdot 00^{*}$ & 0.63 & $0.38^{\star \star \star}$ & 0.44 & 0.32 & 0.04 \\
\hline $20: 4 n-6$ & $18 \cdot 33$ & $2 \cdot 86$ & $17 \cdot 39$ & 1.09 & $18 \cdot 49$ & 1.60 & $13 \cdot 68^{\star \star *} \dagger † \dagger$ & 0.01 & $20 \cdot 12$ & 0.05 & $19 \cdot 22^{*}$ & 0.05 \\
\hline $22: 5 n-3$ & 1.04 & 0.27 & 0.69††† & 0.02 & $0.68^{\star * *}$ & $0 \cdot 01$ & 0.6 & 0.02 & 1.02 & 0.01 & $1 \cdot 61^{\star * *} † \dagger †$ & 0.01 \\
\hline $22: 6 n-3$ & $1 \cdot 44$ & 0.33 & $1 \cdot 70$ & 0.58 & $1 \cdot 10$ & 0.33 & 0.78 & 0.33 & $1 \cdot 20$ & 0.78 & $1 \cdot 45$ & 0.78 \\
\hline SFA & $36 \cdot 13$ & $6 \cdot 42$ & $40 \cdot 18$ & 1.42 & $35 \cdot 84$ & $2 \cdot 39$ & $33 \cdot 75^{\star *}$ & $2 \cdot 39$ & 34.89 & $4 \cdot 2$ & 39.69 & $4 \cdot 22$ \\
\hline MUFA & $26 \cdot 61$ & $4 \cdot 32$ & $23 \cdot 34$ & 1.69 & $34 \cdot 76^{\star * *}$ & 0.62 & $37 \cdot 87^{\star \star *}$ & 1.03 & 28.43 & 0.24 & $26 \cdot 16$ & 0.32 \\
\hline PUFA & $36 \cdot 79$ & $5 \cdot 44$ & $34 \cdot 30$ & $2 \cdot 33$ & $29 \cdot 46^{\star \star *}$ & $2 \cdot 05$ & $26 \cdot 11^{\star *}$ & 0.46 & $36 \cdot 68$ & $1 \cdot 31$ & $32 \cdot 84$ & 0.91 \\
\hline
\end{tabular}

OO, olive oil; HOSO, high-oleic-acid sunflower oil; SFA, saturated fatty acids; MUFA, monounsaturated fatty acids; PUFA, polyunsaturated fatty acids.

Mean values were significantly different from those of the control group ${ }^{*} P<0.05,{ }^{* *} P<0.01,{ }^{* * *} P<0.001$.

Mean values were significantly different from those of the WKY group: $† P<0.05, \dagger \dagger P<0.01, \dagger \dagger \dagger P<0.001$.

$\ddagger$ For details of diets and procedures, see Tables $1-3$ and p. 350. 
effects in the hypertensive state were on 16:0, 18:1 n-9, 20:0 and 22:5 n-3 content. A reduction in palmitic acid and an increase in oleic acid, eicosanoic acid and eicosapentanoic acid in hypertensive animals in relation to control animals (WKY). In the hypertensive and normotensive groups, both diets increased the content in the rat aorta of oleic acid (18:1 $n-9)$, whereas the rise with the OO diet was more significant. A significant decrease in palmitoleic (16:1) and linoleic acid (18:2) was also evident in SHR rats compared with baseline. On the other hand, 20:4 n-6 was reduced by $25 \%$ only in hypertensive animals fed the OO diet. This reduction was significant with respect to both WKY control and WKY fed OO. The differences between the two MUFA diets in the study were a decrease in total saturated fatty acids and polyunsaturated fatty acids in SHR group fed on the OO diet. However, the total MUFA increased in both WKY and SHR rats treated with this diet.

\section{Discussion}

Two clear trends emerge from the present study. First, it is apparent that the oil OO diet attenuates phenylephrineinduced contractions, and reduced vascular reactivity, which would contribute to decreasing vascular tone. In addition, an increase in phospholipid content and changes in fatty acid composition of aorta could be the reason for the improvement of endothelial function.

The vascular smooth muscle in genetic hypertension is characterised by modifications in the signal-transduction system (Thorin-Trescases et al. 1994) and this is accounted for by medial hypertrophy (Sudhir \& Angus, 1990). Phasic contractions of rat aorta induced by phenylephrine were used as an indicator of intracellular $\mathrm{Ca}^{2+}$ release through the inositol 1,4,5-triphosphate receptor pathway. NO selectively inhibits intracellular $\mathrm{Ca}^{2+}$ release stimulated by inositol 1,4,5-triphosphate in vascular smooth muscle ( $\mathrm{Ji}$ et al. 1998). NO has been extensively shown to be a potent vasodilator produced by vascular endothelial cells and NO release is triggered by pharmacologically vasoactive substances such as acetylcholine (Moncada et al. 1991; Moncada \& Higgs, 1993). The intracellular NO in smooth muscle cells involves the generation of cGMP (Rapoport \& Murad, 1983; Moncada et al. 1992), a decrease in Ca mobilization (Twort \& van Breemen, 1988; Komori \& Bolton, 1989) and inhibition of phosphoinositol breakdown (Hirata et al. 1990; Ruth et al. 1993). NO plays an active role in the balance between the contraction and dilation of vascular smooth muscle (Pérez-Guerrero et al. 2000).

In the present study we describe the important role of endothelium in controlling the phenylephrine-induced contraction, as the greater relaxation response to acetylcholine is in relation to the weaker response to phenylephrine, in both preparations from SHR fed with the $\mathrm{OO}$ diet, indicating an improvement of endothelial function of this hypertensive model. It is also clear that the improvement of the endothelium plays an important role in this reduction, inhibiting intracellular $\mathrm{Ca}^{2+}$ release by inositol 1,4,5-triphosphate pathway. The time course of the contraction by phenylephrine was also affected, especially in the preparation from SHR treated with $\mathrm{OO}$, the contraction becoming slower than in SHR control, as well as having a smaller response.

It is known that the degree of unsaturation of dietary oil influences the fatty acid composition of cells, fundamentally in the phospholipids of the cell membrane (Ruiz-Gutiérrez et al. 1990, 1998), and OO feeding leads to changes in lipid metabolism of the vascular compartment that could be favourable in the prevention of thrombosis and atherosclerosis (Navarro et al. 1992). We wanted to verify that the same changes occurred with regard to endothelial function. We can prove, after analysis of lipid composition, that the content of membrane phospholipid, which was found to be reduced significantly $(P<0.001)$ by about $20 \%$ in the animal model of hypertension (SHR) compared with nonhypertensive animals (WKY), was increased significantly $(P<0.01)$ in SHR rats fed on the OO diet approaching the values to those of WKY rats. However, the HOSO diet led to a significant decrease $(P<0.001)$. It is well known that phospholipids, in many cases, are the main components of the cell membranes in a living body. Defects in phospholipid synthesis, besides affecting the absolute amounts of phospholipids per cell, lead to changes in the membrane structure and consequently the function. Except for a few diseases, the information available is very scanty. In relation to the cardiovascular system, phospholipid changes have been observed in blood plasma or serum of patients with heart disease (Cevc, 1993). The plasma levels of total phospholipids are decreased compared with those of normal subjects. Similarly, a decrease in phospholipids content was seen in the present study in hypertensive animals.

Analysis of the fatty acid composition in rat aorta showed a significant increase $(P<0.001)$ of $18: 1$ in aorta lipids obtained from OO- and HOSO-fed rats and lower saturated fatty acid levels in SHR fed with OO. This increase in oleic acid content was probably related to the higher content of oleic acid in the diet of these animals. It has been reported that when endothelial cell cultures are directly supplemented with oleic acid, an increase in its content is found, accompained by a decrease in the saturated acid content (Spector \& Yorek, 1985). Conversely, a lower concentration of arachidonic (20:4) was detected in the same group of rats. It is apparent that the OO diet suppressed the formation of arachidonic acid in aortic smooth muscle phospholipids from SHR rats.

In addition, phospholipids can have a role as diagnostic markers. In general, such diagnostic procedures can be used for detecting changes in part of the phospholipids, usually the fatty-acid chain (Badley et al. 1993). To be exact, when saturated and unsaturated fatty acids of phospholipids have been examined in relation to heart disease (angina, heart attack), arachidonic acid is significantly raised, implying important links with prostaglandin activity and metabolism (Skulladottir et al. 1985).

Therefore, the changes caused by the $\mathrm{OO}$ diet, i.e. the content of total membrane aorta phospholipids (elevation) and the content of arachidonic acid (decrease), may help to explain the vascular protective effect of $\mathrm{OO}$ consumption. The effects cannot be attributed exclusively to the content of MUFA (mainly oleic acid) in the diet, as high-oleicsunflower oil was unable to induce favourable changes. 
Consequently, other components of OO, like polyphenols, not present in HOSO, may be responsible for the beneficial effects on the cardiovascular system. There are references to the protector effect of polyphenols (from red wine) on endothelial dysfunction in human subjects (Cuevas et al. 2000). These polyphenols produce endothelium-dependent relaxation as a result of enhanced NO synthesis rather than enhanced biological activity of $\mathrm{NO}$ or protection against breakdown by $\mathrm{O}_{2}^{-}$(Andriambeloson et al. 1997; Andriantsitohaina 1999).

We conclude that $\mathrm{HOSO}$ and $\mathrm{OO}$, providing a similar concentration of MUFA, have different effects on vascular reactivity of isolated rat aorta and lipid composition and fatty acid composition of phospholipids of intima aorta. Only the chronic feeding of the OO diet was able to attenuate vascular response of rat aorta, probably through an improvement of endothelial function.

\section{Acknowledgements}

We wish to thank Aceites Toledo S.A. and Koipe S.A. for kindly providing the oils used in this study. We also gratefully acknowledge the technical assistance of $\mathrm{Mr}$. Antonio Martin Rodriguez. The study was supported by grants (ALI96-0456 and ALI99-0863) from Comision Interministerial de Ciencia y Tecnologia (CICYT).

\section{References}

Andriambeloson E, Kleschyov AL, Muller B, Beretz A, Stoclet JC \& Andriantsitohaina R (1997) Nitric oxide production and endothelium-dependent vasorelaxation induced by wine polyphenols in rat aorta. British Journal of Pharmacology 120, $1053-1058$

Andriantsitohaina R (1999) Regulation of vascular tone by plant polyphenols: role of nitric oxide. Genetics, Physiology and Biophysics 18, Suppl. 1, 3-5.

Alvarez de Sotomayor M, Pérez-Guerrero C, Herrera MD \& Marhuenda E (1999) Effects of chronic treatment with simvastatin on endothelial dysfunction in spontaneously hypertensive rats. Journal of Hypertension 17, 769-776.

Arce L, Rios A \& Valcarcel M (1998) Determination of anticarcinogenic polyphenols present in green tea using capillary electrophoresis coupled to a flow injection system. Journal of Chromatography A 827, 113-120.

Badley RA, Davis PJ \& Tolley DM (1993) Phospholipids in diagnosis. In Phospholipids Handbook, pp. 833-853 [G Cevc, editor]. New York, NY: Marcel Dekker, Inc.

Bazan E, Campbell AK \& Rapoport RM (1993) Effects of protein kinase $\mathrm{C}$ activation on norepinephrine-induced phosphatidylinositide hydrolysis in intact rat aorta. European Journal of Pharmacology 245, 173-177.

Bohr DF \& Webb RC (1988) Vascular smooth muscle membrane in hypertension. Annual Review of Pharmacology and Toxicology 28, 389-409.

Cevc G (editor) (1993) Phospholipids Handbook, New York, NY: Marcel Dekker, Inc.

Cuevas AM, Guasch V, Castillo O, Irribarra V, Mizon C, San Martin A, Strobel P, Perez D, Germain AM \& Leighton F (2000) A high-fat diet induces and red wine counteracts endothelial dysfunction in human volunteers. Lipids 35, 143-148.

De Schrijver R \& Vermeulen D (1991) Separation and quantification of phospholipids in animal tissues by Iatroscan TLC/FID. Lipids 26, 74-75.
Egashira K, Suzuki S, Hirooka Y, Kai H, Sugimachi M, Imaizumi T \& Takeshita A (1995) Impaired endothelium-dependent vasodilation of large epicardial and resistance coronary arteries in patients with essential hypertension: different responses to acetylcholine and substance P. Hypertension 25, 201-206.

Folch J, Lees M \& Sloane-Stanley GH (1957) A simple method for the isolation and purification of total lipides from the animal tissues. Journal of Biological Chemistry 26, 497-509.

Garcia Regueiro JA, Gilbert J \& Diaz I (1994) Determination of neutral lipids from subcutaneous fat cured ham by capillary gas chromatography and liquid chromatography. Journal of Chromatography A 667, 225-233.

Herrera MD, Zarzuelo A, Jiménez J, Marhuenda E \& Duarte J (1996) Effects of flavonoids on rat aortic smooth muscle contractility: Structure-activity relationships. Genetics and Pharmacology 27, 273-277.

Hirata M, Kohse KP, Chang CH, Ikebe TJ \& Murad F (1990) Mechanism of cyclic GMP inhibition of inositol phosphate formation in rat aorta segment and cultured bovine aortic smooth muscle cells. Journal of Biological Chemistry 265, 1268-1273.

Ji J, Benishin CG \& Pang PK (1998) Nitric oxide selectively inhibits intracellular $\mathrm{Ca}^{++}$release elicited by inositol trisphosphate but not caffeine in rat vascular smooth muscle. Journal of Pharmacology and Experimental Therapeutics 285, 16-21.

Keys A (1995) Mediterranean diet and public health: personal reflections. American Journal of Clinical Nutrition 61, $1321 \mathrm{~S}-1323 \mathrm{~S}$.

Komori S \& Bolton TB (1989) Actions of guanine nucleotides and cyclic nucleotides on calcium stores in single patch clamped smooth muscle cells from rabbit portal vein. British Journal of Pharmacology 97, 973-982.

Kramer JK, Blais L, Fouchard RC, Melnyk RA \& Kallery KM (1997) A rapid method for the determination of vitamin $\mathrm{E}$ forms in tissues and diet by high-performance liquid chromatography using a normal-phase diol column. Lipids 32, 323-330.

Massaro M, Carluccio MA \& De Caterina R (1999) Direct vascular antiatherogenic effects of oleic acid: a clue to the cardioprotective effects of the Mediterranean diet. Cardiologia 44, $507-513$

Moncada S \& Higgs EA (1993) The L-arginine-nitric oxide pathway. New England Journal of Medicine 329, 2002-2012.

Moncada S, Palmer RMJ \& Higgs EA (1991) Nitric oxide: physiology, pathophysiology, and pharmacology. Pharmacology Reviews 43, 109-142.

Moncada S, Reed DD, Schulz R \& Palmer RMJ (1992) Development and mechanism of a specific supersensitivity to nitrovasodilators after inhibition of vascular nitric oxide synthesis in vivo. Proceedings of the National Academy of Science, USA 88, 2166-2170.

Monteodoro GF, Servili M, Baldioli M \& Miniati E (1992) Simple and hydrolyzable phenolic compounds in virgin olive oil. Their extraction, separation and quantitative and semiquantitative evaluation by HPLC. Journal of Agriculture and Food Chemistry 40, 1571-1576.

Muriana FJG, Ruiz-Gutiérrez V, Blaya JA \& Bolufer J (1995) Phospholipid fatty acid composition of hepatopancreatic brushborder membrane vesicles fron the prawn Panaeus japonicus. Biochimie 77, 190-193.

Navarro MD, Hortelano P, Periago JL \& Pita ML (1992) Effect of dietary olive and sunflower oils on the lipid composition of the aorta and platelets and on blood eicosanoids in rats. Arteriosclerosis and Thrombosis 12, 830-835.

Osugi S, Shimamura K \& Sunano S (1990) Decreased modulation by endothelium of noradrenaline-induced contractions in aorta from stroke-prone spontaneously hypertensive rats. Archives of Internal Pharmacodynamics 305, 86-99.

Pérez-Guerrero C, Alvarez de Sotomayor M, Herrera MD \& 
Marhuenda E (2000) Endothelium modulates contractile response to simvastatin in rat aorta. Zeitschrift für Naturforschung 55, 121-124.

Rapoport RM \& Murad F (1983) Agonist-induced endotheliumdependent relaxation in rat thoracic aorta may be mediated through cyclic GMP. Circulation Research 62, 961-964.

Ruiz-Gutiérrez V, Molina MT \& Vázquez CM (1990) Comparative effects of feeding different fats on fatty acid composition of major individual phospholipids of rat hearts. Annals of Nutrition and Metabolism 34, 350-358.

Ruiz-Gutiérrez V, Montero E \& Villar J (1992) Determination of fatty acid and triacylglycerol composition of human adipose tissue. Journal of Chromatography B 581, 171-178.

Ruiz-Gutiérrez V, Perona JS, Pacheco YM, Muriana FJ \& Villar J (1999) Incorporation of dietary triacylglycerols from olive oil and high-oleic sunflower oil into VLDL triacylglycerols of hypertensive patients. European Journal of Clinical Nutrition 53, 687-693.

Ruiz-Gutiérrez V, Muriana FJG, Guerrero A, Cert AM \& Villar J (1996) Plasma lipids, erythrocyte membrane lipids and blood pressure of hypertensive women after dietary oleic acid from two different sources. Journal of Hypertension 14, 1483-1490.

Ruiz-Gutiérrez V, Muriana FJG, Maestro R \& Graciani E (1995) Oleuropein and lipid and fatty acid composition of rat heart. Nutrition Research 15, 37-51.

Ruiz-Gutiérrez V, Muriana FJG \& Villar J (1998) El aceite de oliva virgen en la prevención de enfermedades cardiovasculares perfil lipídico en plasma y composición lipídica de la membrana de eritrocito humano. Grasas y Aceites 49, 9-29.

Ruth P, Wang GX, Boekhoff I, May B, Pfeifer A, Penner R, Korth M, Breer M \& Hoffmann F (1993) Transfected cGMPdependent protein kinase suppresses calcium transients by inhibition of inositol 1,4,5-triphosphate production. Proceedings of the National Academy of Science, USA 90, 2623-2627.

Shirasaki Y, Kolm P, Nickols GA \& Lee TJ-F (1988) Endothelial regulation of cyclic GMP and vascular responses in hypertension. Journal of Pharmacology and Experimental Therapeutics 245, 53-58.

Silver PJ, Cumiskey WR \& Harris AL (1992) Vascular protein kinase C in Wistar-Kyoto and spontaneously hypertensive rats. European Journal of Pharmacology 212, 143-149.

Skulladottir G, Hardanson T \& Sigfusson N (1985) Arachidonic acid levels in serum phospholipids of patients with angina pectoris or fatal myocardial infarction. Acta Medica Scandinavica 218, 55-58.

Spector AA \& Yorek MA (1985) Membrane lipid composition and cellular function. Journal of Lipid Research 26, 1015-1035.

Sudhir K \& Angus JA (1990) Contractile responses to alpha 1-adrenoceptor stimulation during maturation in the aorta of the normotensive and spontaneously hypertensive rat: relation to structure. Clinical and Experimental Pharmacology and Physiology 17, 69-82.

Sulpioce JC \& Ferezou J (1984) Squalene isolation by HPLC and quantitative comparison by HPLC and GLC. Lipids 19, 631-635.

Sunano S, Osugi O \& Shimamura K (1989) Blood pressure and impairment of endothelium-dependent relaxation in spontaneously hypertensive rats. Experientia 45, 705-708.

Taddei S, Virdis A, Mattei P, Ghiadoni L, Gennari A, Fasolo CB, Sudano I \& Salvetti A (1995) Aging and endothelial function in normotensive subjects and patients with essential hypertension. Circulation 91, 1981-1987.

Tesfamariam B \& Halpern W (1988) Endothelium-dependent and endothelium-independent vasodilation in resistance arteries from hypertensive rats. Hypertension 11, 440-444.

Thorin-Trescases N, Hamilton CA, Jardine E \& Reid JL (1994) Signal transduction mechanisms of the vasoconstriction in hypertension. European Journal of Pharmacology $\mathbf{2 6 8}$, 199-207.

Triggle CR \& Laher I (1985) A review of changes in vascular smooth muscle functions in hypertension: isolated tissue versus in vivo studies. Canadian Journal of Physiology and Pharmacology 63, 355-365.

Tsimikas S, Philis-Tsimikas A, Alexopoulos S, Sigari F, Lee C \& Reaven PD (1999) LDL isolated from Greek subjects on a typical diet or from American subjects on an oleatesupplemented diet induces less monocyte chemotaxis and adhesion when exposed to oxidative stress. Arteriosclerosis Thrombosis and Vascular Biology 19, 122-130.

Turla MB \& Webb RC (1987) Enhanced vascular reactivity to protein kinase $\mathrm{C}$ activators in genetically hypertensive rats. Hypertension 9, III150-III154.

Turla MB \& Webb RC (1990) Augmented phosphoinositide metabolism in aortas from genetically hypertensive rats. American Journal of Physiology 258, H173-H178.

Twort CHC \& van Breemen C (1988) Cyclic guanosine monophosphate-enhanced sequestration of $\mathrm{Ca}^{2+}$ by sarcoplasmic reticulum in vascular smooth muscle. Circulation Research 62, 961-964.

Visioli F \& Galli C (1994) Oleuropein protects low density lipoprotein from oxidation. Life Sciences 55, 1965-1971.

Visioli F \& Galli C (1995) Natural antioxidants and prevention of coronary heart disease: the potential role of olive oil and its minor constituents. Nutrition and Metabolism in Cardiovascular Disease 5, 306-314. 